\title{
Knowledge, Attitude, and Practice of Menstrual Hygiene in Women Aged 13-45 Years Attending Hind Institute of Medical Sciences, Sitapur: A Cross-sectional Study
}

\author{
Rupali Gupta ${ }^{1}$, Shweta Mishra ${ }^{2}$, Abhilasha Parihar $^{3}$, Rinki Kumari $^{4}$
}

\begin{abstract}
Background and aims and objectives: There is a substantial lacuna in the awareness of menstruation and menstrual hygiene practice among young girls and women of reproductive age. Menstruation is a normal hormonal process and the leading indicator of women's reproductive age groups' reproductive health. Inadequate knowledge about menstrual hygiene influences education practice, social activity, environment, and women's daily activities. This study evaluates women's hygiene practices in the Sitapur district among women aged 13-45 years, evaluates their knowledge of menstrual hygiene, and promotes their knowledge about menstrual hygiene.

Materials and methods: This was hospital-based cross-sectional research conducted in the woman age group of 13-45 years attending Gynecology's outpatient department. A predesigned, pretested, semi-structured questionnaire has been used as a questionnaire survey. The interview process has been used for data collection and obtaining informed consent from the participants. The SPSS $20 \mathrm{v}$ software analyzed data. Results: The mean age of participants was $29.00 \pm 9.60$ years; $76.8 \%$ of participants were not aware of menstruation before attaining menarche, around $23.78 \%$ were not known about the cause of menstruation, and $75.20 \%$ source of the blood of menstruation cycle in a rural area. In the rural area, only $4.72 \%$ used only sanitary pads, and the majority of participants, $79.39 \%$, used old clothes, whereas $75 \%$ used sanitary pads in the urban. Only water used for cleaning the external genitalia was practiced by $52.36 \%$ of rural area subjects. Meaningfully deplorable menstrual hygiene practices associated with rural participates.

Conclusion: The educational and communication program for public health care focusing on menstrual hygiene must be strengthened. Educational awareness and very well programs will play a key role in implementing health education in women.

Keywords: Awareness, Menstrual hygiene, Menstruation, Reproductive women.

International Journal of Infertility and Fetal Medicine (2021): 10.5005/jp-journals-10016-1224
\end{abstract}

\section{INTRODUCTION}

There is a substantial lack of awareness of young girls, even adult females, about menstruation. Numerous research studies have shown this discrepancy and have shown a low awareness among girls about menstruation. ${ }^{1-4}$ Menstruation is a natural, normal female body physiological process that is the main sign of womenfolk's reproductive condition in the reproductive age group. ${ }^{1}$ The word "menstruation" (period/menstruation periodmenstruation cycle-MC) was derived from the Latin term "MENSES" meaning moon, and that defines - it as a cyclical discharge of blood and tissue debris from the uterus that repeats in nonpregnant breeding-age women after 28 days per month. ${ }^{1,5,6}$

Many erroneous behaviors and misconceptions have been connected with menstruation since ancient times, resulting in adverse health effects (affect the quality of life). ${ }^{1,2}$ Several clinical survey studies have shown that most adolescent girls or young women do not have full precise knowledge of the menstrual cycle and its hygiene habits. They get information from a specific source-mothers, television, peers, teachers, and relatives provide valuable information about $\mathrm{MC}^{1,6-8}$

The hygiene status of women during $M C$ is not maintained in rural areas, not only in India but also in other developing countries, and it harms women's health. ${ }^{6,9,10}$ Different clinical studies have exposed that females avoid baths during MC, and also, they are restricted consumption to specific diets. ${ }^{6,11}$ Numerous clinical health conditions such as cervical cancer, miscarriage, ectopic pregnancy, sexually transmitted infection (STI), and reproductive tract infection
${ }^{1-3}$ Department of Obstetrics and Gynaecology, Hind Institute of Medical Sciences, Mau Ataria, Uttar Pradesh, India

${ }^{4}$ Department of Microbiology, Hind Institute of Medical Sciences, Mau Ataria, Uttar Pradesh, India

Corresponding Author: Rinki Kumari, Department of Microbiology, Hind Institute of Medical Sciences, Mau Ataria, Uttar Pradesh, India, Phone: +91 7905101562, e-mail: rinkiv3@gmail.com

How to cite this article: Gupta R, Mishra S, Parihar A, et al. Knowledge, Attitude, and Practice of Menstrual Hygiene in Women Aged 13-45 Years Attending Hind Institute of Medical Sciences, Sitapur: A Crosssectional Study. Int J Infertil Fetal Med 2021;12(3):49-54.

Source of support: Nil

Conflict of interest: None

(RTI) emerge from unhygienic practices and often affect the social well-being of females of reproductive age. $6,12,13$

Shingade and his colleagues reported in 2016 that $>70 \%$ of women's RTIs are due to unhygienic practices; it can also lead to fetal abortion. ${ }^{6,14}$ Lack of menstrual hygiene awareness affects not only social, health, physical, and educational activities, but also the environment; improper disposal (keeping inside the washroom, indiscriminate throwing in ponds/open areas or drains) creates an environmental hazard and impacts health indirectly (not only female but all living ones). ${ }^{14,15}$

Moreover, women are unaware of menstrual hygiene practices (did not get adequate knowledge from primary sources), especially

(c) Jaypee Brothers Medical Publishers. 2021 Open Access This article is distributed under the terms of the Creative Commons Attribution 4.0 International License (https://creativecommons.org/licenses/by-nc/4.0/), which permits unrestricted use, distribution, and non-commercial reproduction in any medium, provided you give appropriate credit to the original author(s) and the source, provide a link to the Creative Commons license, and indicate if changes were made. The Creative Commons Public Domain Dedication waiver (http://creativecommons.org/publicdomain/zero/1.0/) applies to the data made available in this article, unless otherwise stated. 
in rural areas of developing countries such as India, and cannot discuss MC because of social prohibition. ${ }^{16}$ However, menstrual hygiene activity is a public health issue, but no one takes significant action because of an undesirable circumstance (ignored by politicians, decision-makers). ${ }^{17,18}$ Therefore, good menstrual hygiene habits are also necessary during the menstrual period, including good sanitary pads, adequate genital cleaning, regular bathing, and eating a good diet. ${ }^{6,18}$ With this background, the current research was conducted to evaluate the habits and knowledge of menstrual hygiene among women of reproductive age group (different age group).

\section{Aims and Objectives}

- Evaluation of menstrual awareness, attitudes, and self-care during menstruation in women aged $13-45$ years in rural areas of Sitapur, UP.

- To identify the prevalent menstrual hygiene patterns in rural communities.

- To determine the relative contribution of participants and their mothers' educational status to the use of unhygienic activities during menstruation.

\section{Materials and Methods}

The present research was performed by the Department of Obstetrics and Gynaecology at Hind Institute of Medical Sciences, Ataria, Sitapur, UP; conducted from July 2019 to September 2019. The study duration consisted of 3 months. All females of the reproductive age group (13-45 years) attending routine gynecology OPD (including the patients' female relatives accompanying them) in July 2019 were included in the study after taking their consent and selected by systematic random sampling method.

The questioner was used to collect data from subjects on their sociodemographic profile, effects, restrictions imposed, menstrual awareness, and about use of sanitary napkins, feminine health, and hygiene. The confidentiality of the data gathered during the analysis was preserved. Face-to-face discussion (interview method) was done for data collection, and before the start of the study, it was approved by the Institutional Ethics Committee, Hind Institute of Medical Sciences, Sitapur (IEC/IRB NO: HIMS/IRB/2019-20/04 DATED 10-06-2019).

\section{Inclusion Criteria}

- Females of the age group of 13-45 years from rural areas to OPD of Hind Institute of Medical Sciences, Sitapur.

\section{Exclusion Criteria}

- Physically and mentally handicapped women.

- The research omitted those participants who disapproved of the study, who was seriously ill, breastfeeding and lactating women who did not reach menstruation.

\section{Subjects Sample Size Calculation}

Eighty-one percent of Uttar Pradesh women do not know about the sanitary pad as they use cloths during their menstrual period, according to NFHS IV (2015-2016). Using the prevalence of menstrual hygiene practice and hygiene products like sanitary pads or napkins, antiseptic agents, either separately or combined with reusable cloth, the sample size was then calculated using the formula, $n=p \times(100-p) \times z / d^{19,20}$ (where $p$ is the anticipated prevalence; $d$ is the desired precision; $z$ is the standard distribution of the significance level $)$ then, sample size $=(1.96 \times 1.96 \times 0.81 \times$ 0.19 ) $/ 0.05 \times 0.05=237$ (the minimum sample size was found to be 237) at $5 \%$ level of significance.

\section{Statistical Analysis}

In a Microsoft Excel document, the collected data were entered and evaluated using the SPSS 20v program. Frequencies were expressed as percentages, using bar charts and pie diagrams to show the variables' distribution. In mean and SD, continuous variables were expressed. The relation between variables was verified by the Chisquare test and found significant was $p<0.05$.

\section{Results}

Out of the total 237 subjects, the majority $(98.31 \%)$ belonged to rural areas, whereas $1.68 \%$ urban areas. The mean age of subjects was $29.00 \pm 9.67$ years. Table 1 demonstrates that women have participated in different age groups (13-45 years old) in the present study. Most of the females were in the age group between 19 years and 26 years $(37.13 \%)$ mean age was $(21.93 \pm 2.42)$ followed by $13-18$ years (29.53\%); the mean age was (15.46 \pm 1.63$)$ (Fig. 1).

Table 2 shows that most of the majority (98.31\%) of subjects belonged to rural areas (most of them close to the hospital's village), while $17.39 \%$ were from urban areas. Around 149 (62.86\%) out of 237 women were married, whereas $37.13 \%$ were unmarried. The majority of them had an education level underclass 10 that is $88.18 \%$, whereas less in the above class 10 , i.e., $11.81 \%$. Most of the mothers were illiterate, $33.33 \%$, whereas primary school $(25.73 \%)$, middle school education (18.98\%), and secondary school (10.54\%),

Table 1: Age group-wise distribution of participates

\begin{tabular}{lllll}
\hline Age group (in years) & Total $n=237(\%)$ & Mean & Median & $S D \pm$ \\
\hline $13-18$ & $70(29.53)$ & 15.46 & 15 & 1.639 \\
$19-26$ & $88(37.13)$ & 21.93 & 21 & 2.425 \\
$27-32$ & $36(15.18)$ & 29.53 & 30 & 1.521 \\
$33-38$ & $23(9.70)$ & 35.61 & 36 & 1.828 \\
$39-45$ & $20(8.43)$ & 43.50 & 45 & 2.065 \\
\hline
\end{tabular}

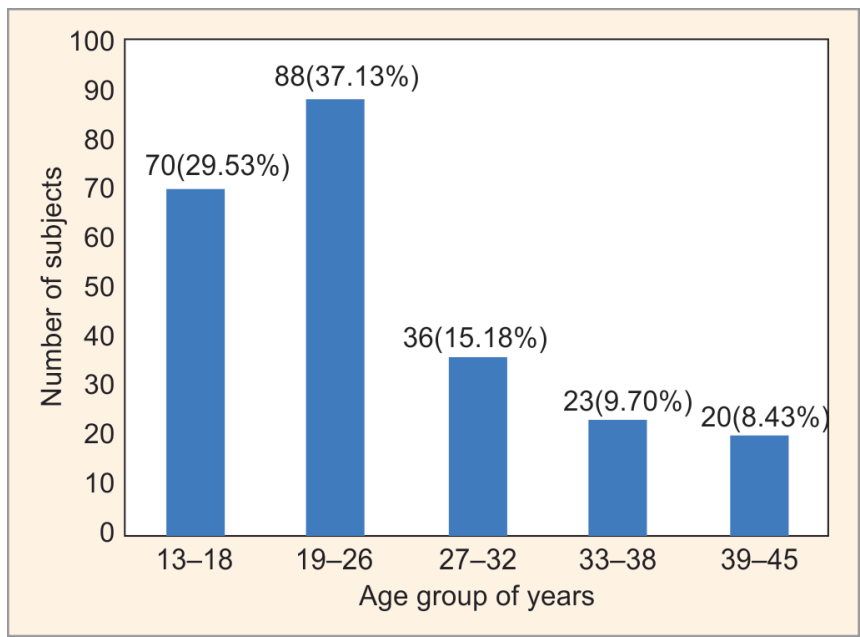

Fig. 1: Distribution of subjects as per age group (with percentage) 
Table 2: Distribution of respondents according to their sociodemographic information $(n=237)$

\begin{tabular}{|c|c|}
\hline Sociodemographic profile & $N(\%)$ \\
\hline \multicolumn{2}{|l|}{ Residence (area) } \\
\hline Urban & $4(17.39)$ \\
\hline Rural & $233(98.31)$ \\
\hline \multicolumn{2}{|l|}{ Marital status } \\
\hline Married & $149(62.86)$ \\
\hline Unmarried & $88(37.13)$ \\
\hline \multicolumn{2}{|l|}{ Educational status } \\
\hline Underclass 10 & 209 (88.18) \\
\hline Above class 10 & $28(11.81)$ \\
\hline \multicolumn{2}{|l|}{ Mother's literacy } \\
\hline Illiterate & $79(33.33)$ \\
\hline Primary school & $61(25.73)$ \\
\hline Middle school & $45(18.98)$ \\
\hline Secondary school & $25(10.54)$ \\
\hline \multicolumn{2}{|l|}{ Religious } \\
\hline Hindu & $198(83.54)$ \\
\hline Muslim & $39(16.45)$ \\
\hline \multicolumn{2}{|l|}{ Type of family } \\
\hline Joint & $229(96.62)$ \\
\hline Nuclear & $8(3.37)$ \\
\hline \multicolumn{2}{|c|}{$\begin{array}{l}\text { Socioeconomic status (modified BG Prasad scale-updated Januar) } \\
\text { 2018) }\end{array}$} \\
\hline Class I (upper middle) & $1(0.42)$ \\
\hline Class II (middle) & $12(5.06)$ \\
\hline Class III (lower middle) & $92(38.81)$ \\
\hline Class IV (lower) & $132(55.69)$ \\
\hline \multicolumn{2}{|l|}{ Toilet facility } \\
\hline Toilet in house & $36(15.18)$ \\
\hline Common toilet & 91 (38.39) \\
\hline Open space outside & $110(46.41)$ \\
\hline \multicolumn{2}{|l|}{ Household water supply } \\
\hline Piped supply at home & $96(40.50)$ \\
\hline Water stored & $116(48.94)$ \\
\hline No supply & $25(10.54)$ \\
\hline
\end{tabular}

respectively. About $83.54 \%$ of the females were Hindus, whereas only $16.45 \%$ belong to Muslims; $96.62 \%$ were from Joint, whereas significantly less $3.37 \%$ from nuclear families in the present finding. Most of the participants (55.69\%) were from class IV (lower class families), followed by the lower middle class (class III) (38.81\%) as per the modified 2018 BG Prasad scale. The majority of the participants (46.41\%) go outside the house for the toilet, and $48.94 \%$ had water stored in their homes.

According to the menstrual background (including its symptoms), the sample population's distribution is seen in Table 3. In the present study, most participants had a bleeding time of fewer than 3 days (74.68\%), and $21.51 \%$ of subjects had less than five bleeding times. The majority of participants (75.10\%) registered an abnormal or irregular menstrual cycle, whereas only $24.89 \%$ of participates had a regular menstruation period. Around $27.84 \%$ of subjects who had excess bleeding complained. Through the menstruation period, most participates (49.72\%) had stomach or abdominal pain accompanied by fatigue or weakness $(27.84 \%)$ and
Table 3: Distribution of study population according to menstrual history $(n=237)$

\begin{tabular}{lc}
\hline Menarche and menstruation cycles history & $N(\%)$ \\
\hline Duration of MC (days) & $9(3.79)$ \\
$<3$ & $177(74.68)$ \\
$>3$ & $51(21.51)$ \\
$>5$ & \\
Regularity of MC & $59(24.89)$ \\
$\quad$ Regular & $178(75.10)$ \\
Irregular & \\
Appear symptoms during menstruation time & $11(4.64)$ \\
Vomiting & $9(3.79)$ \\
Nausea & $65(27.84)$ \\
Excess bleeding & $15(6.32)$ \\
Headache & $66(27.87)$ \\
Weakness & $118(49.78)$ \\
Pain abdomen & $10(4.21)$ \\
Breast pain & $8(3.37)$ \\
Itching around genital & \\
Restriction (out of 237) & $98(41.35)$ \\
House task & $118(49.78)$ \\
Religious activity & $115(48.52)$ \\
Attaining other functions and activities & \\
(marriage, did not go school, and play) & $129(54.43)$ \\
Separate sleeping & $127(53.58)$ \\
Separate eating & \\
\hline
\end{tabular}

other symptoms like headache (6.32\%), vomiting (4.64\%), nausea (3.79\%), and few participates $4.21 \%$ had to feel breast pain and soma were, itching around genital (3.37\%).

Concerning various types of restrictions during menstruation cycles; around, $54.43 \%$ of women sleep separately, $49.78 \%$ of women were restricted to attend some religious event, $41.35 \%$ of women did not perform some household tasks, several girls did not even allow to play, $49.52 \%$ of girls did not attend any other marriages, and occasions (did not go to school) including different forms of prohibitions during menstrual periods, seen in Table 3.

Table 4 shows awareness of study participants about the menstruation cycle and menstrual hygiene was found, as $41.35 \%$ of the participants knew about the type of napkin to be used, and $41.35 \%$ of them were aware of cleaning perineum while changing pads or after urination. Around $36.28 \%$ of them were aware of the problems likely to arise due to unhygienic practices, whereas awareness about sanitary napkins before menarche was low (23.20\%). The majority of participants (98.73\%) knew about menstruation as indicating fertility, whereas only $24.89 \%$ of women were aware of proper sanitary products. Around $90.71 \%$ knew about menstruation's cause, while $67.93 \%$ of participants were aware of the age of normal cessation of menstruation. Similarly, $81.85 \%$ of subjects were aware of sanitary pads by other female family members; whether cost constraints are present for using sanitary pads, they knew $83.12 \%$ of subjects. Through this study was found as $83.54 \%$ of participates aware that menstrual blood being impure. Around $91.13 \%$ of subjects knew about normal monthly menstruation duration, whereas $24.89 \%$ of participants were aware of hot or cold food affecting the menstrual cycle. Regarding awareness, about $75.52 \%$ of participates had reported 
Table 4: Awareness of study participants about menstrual hygiene $(n=237)$

\begin{tabular}{lc}
\hline $\begin{array}{l}\text { Awareness questions about menstruation cycle and } \\
\text { menstrual hygiene }\end{array}$ & Number (\%) \\
\hline Aware of cleaning perineum while changing pads & $112(47.25)$ \\
Type of napkin ideally to be used & $98(41.35)$ \\
Aware of using sanitary napkin before menarche & $55(23.20)$ \\
Aware of cleaning perineum after urination & $98(41.35)$ \\
Aware about problems likely to arise due to & $86(36.28)$ \\
unhygienic practice & \\
Normal monthly duration of menstruation & $216(91.13)$ \\
Menstrual blood being considered impure & $198(83.54)$ \\
Proper sanitary products & $59(24.89)$ \\
Cause of menstruation & \\
$\quad$ Natural & $179(75.52)$ \\
A disease & $14(5.90)$ \\
Do not know & $29(12.23)$ \\
$\quad$ God curse & $15(6.3)$ \\
Origin of menstrual blood & $155(65.40)$ \\
Age of normal cessation of menstruation & $161(67.93)$ \\
Hot or cold food affecting the menstrual cycle & $59(24.89)$ \\
Menstruation as indicating fertility & $234(98.73)$ \\
Whether cost constraints are present for using & $197(83.12)$ \\
sanitary pads & $194(81.85)$ \\
Use of sanitary pads by other female members in \\
the family
\end{tabular}

that menstruation is a natural biological female body process, and around $6.3 \%$ knew that it is due to god curse (Table 3 ).

In the present study, it was also found that $75.00 \%$ in an urban area and $4.72 \%$ in the rural area used sanitary pad, whereas new cloth $15.87 \%$ in the urban area and $25.00 \%$ in the rural area and the majority of subjects $79.39 \%$, used old cloths in the rural areas during menstruation. Regarding the menstrual hygiene practices, it was found that $57.08 \%$ of subjects wash genitalia daily in rural and urban, the majority of participants cleaned genitalia daily (Table 5).

Regarding cleaning material, about 52.36, 41.02, and $6.43 \%$ participate in rural cleaning with water, soap and water, and antiseptic, respectively, whereas $100 \%$ in urban areas used antiseptic for cleaning external genitalia. More than $72.10 \%$ of rural areas burnt the used cloth/pad of menstruation, and only $27.89 \%$ threw it in waste, whereas $100 \%$ of subjects threw pads in the waste, regarding the place of drying cloth if they re-used after washing, most subjects (72.96\%) of rural area dried in sunlight and $27.03 \%$ inside the house.

Figure 1 shows the subjects' distribution in the different age groups. The majority (37.19\%) of participants had reported in the 19-26 years, whereas less percentage $(9.70 \%)$ in the age group 33-38 years. Figure 2 shows the restrictions during menstruation across rural and urban areas. Avoiding worship (10.23 vs $5.12 \%$ ), restriction in diet (11.29 vs $3.25 \%)$. Avoiding games were more common in rural areas ( 9.86 vs $5.74 \%$ ), whereas staying at home (6.6 vs $0.0 \%$ ) and avoiding social function ( 9.8 vs $1.2 \%$ ) were more common in rural areas. Figure 3 shows the source of menstruation across rural and urban areas. Uterus source (68.21 vs $50.00 \%)$, urinary bladder ( 8.15 vs $00 \%)$, vagina ( 6.86 vs $25.00 \%)$, abdominal (3.86 vs $00 \%)$, kidney (38.19 vs $00 \%)$, and some were do not about the source of menstruation, were more common in rural areas. Figure 4
Table 5: Association of awareness with multiple criteria for menstrual hygiene practices

\begin{tabular}{llll}
\hline S. no. & Questions & Rural $n=233(\%)$ & Urban $n=4(\%)$ \\
\hline 1. & What material you use & \\
during menstruation & & \\
a. & Sanitary pad & $11(4.72)$ & $3(75)$ \\
b. & New cloth & $37(15.87)$ & $1(25)$ \\
c. & Old cloth & $185(79.39)$ & 0 \\
2. & Cleaning of external & \\
& genitalia & \\
a. & Daily & \\
b. & Only MC & $133(57.08)$ \\
2. & How you clean external & \\
& genitalia & $99(42.48)$ \\
a. & Only water & $122(52.36)$ \\
b. & Soap and water & $96(41.20)$ & \\
c. & Antiseptic & $15(6.43)$ \\
3. & Method of disposal & $4(100)$ \\
a. & Burn & $168(72.10)$ \\
b. & Throw in waste & $65(27.89)$ & $4(100)$ \\
4. & Places of drying cloth if & & \\
& re-used after washing & & \\
a. & Inside house & $63(27.03)$ & 0 \\
b. & Outside in sunlight & $170(72.96)$ & 0 \\
\hline
\end{tabular}

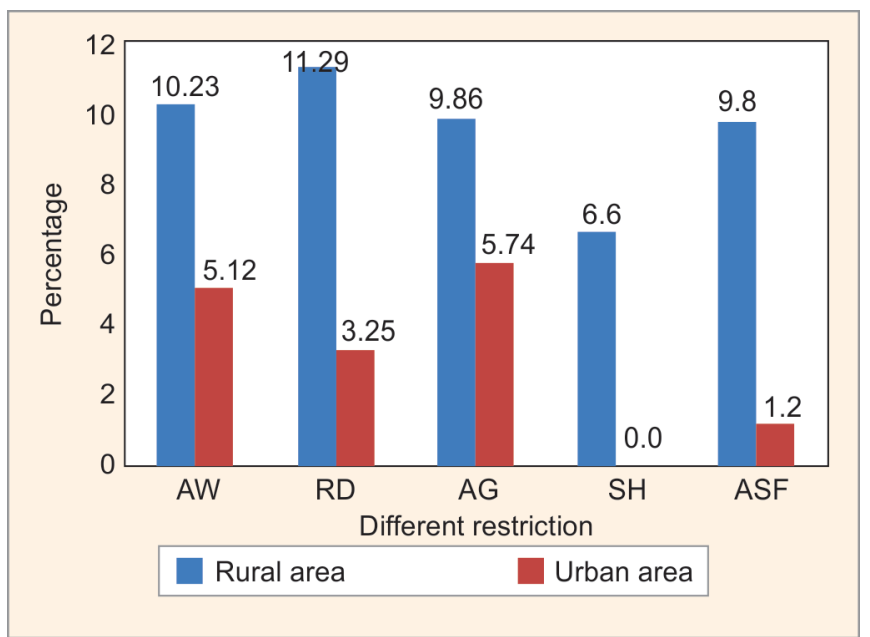

Fig. 2: Restriction during menstruation (in both area rural and urban in respect to $A W$, avoiding worship; $R D$, restriction in diet; $A G$, avoiding games; $\mathrm{SH}$, staying at home; ASF, avoiding social function)

represents the majority $(72.10 \%)$ of rural participates who had to burn menstruation pads.

\section{Discussion}

This study aims to discuss menstrual hygiene practices among women of reproductive age (mainly rural areas). The mean age was $29.0 \pm 9.66$, most of which were married, similar to those reported by Balamurugan et al., where the majority (33.33\%) of the study population was aged 27-45 years while they were aged 21-26 (23.62\%) and overall subjects, around $62.86 \%$ were married. ${ }^{21,22}$ Similar findings were also reported by Mathiyalagen et al., ${ }^{22}$ where the subjects' mean age was $28.2 \pm 7.5$, and most were married. 


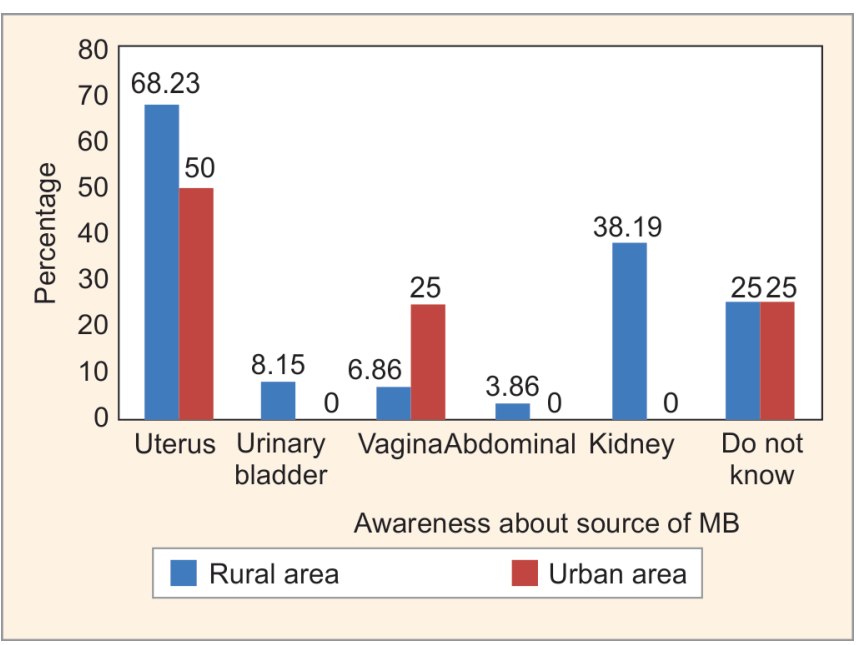

Fig. 3: Source of menstruation blood (compare between rural and urban subjects)

Regarding the place of subjects, the majority of participates (98.31\%) from the rural area and this high than the performed study by Paul et al., ${ }^{5}$ where findings had been reported (40.2\%) and in the present study resulted indicated that most of the family were joint $(96.62 \%)$, whereas $83.1 \%$ were from nuclear families had been reported by Mathiyalagen et al. ${ }^{22}$ The females having school education (under class 10 th) was about $88.88 \%$ in our study, and it was higher than both reports Thakur et al., ${ }^{6}$ and Misra et al., ${ }^{11}$ where it was only about 30 and $15 \%$, respectively.

In Indian different communities, and they follow a different type of restrictions during menstruation. In our study, most Hindus who participated (83.54\%) have been reported and supported by Mathiyalagen et al., ${ }^{22}$ where $96.3 \%$ of participants were Hindus. Around 54.43 and $49.78 \%$ of females were sleeping separately, restricted for the religious task, and this result very similar to the finding reported by Mathiyalage et al. ${ }^{22}$ where females were asked to sleep separately (58.7\%) and followed by restricting religious activities (44.6\%).

The present study has reported that $74.68 \%$ had $>3$ days $(<5$ days) of menstrual flow, and this result was similar to the findings by Balasubramanian ${ }^{21}$ and Juyal et al. ${ }^{17}$ The finding of the present study regarding the cause of menstruation was unknown to a few participates (21.29\%). The result was near-similar to the study finding by Langer et al. ${ }^{13}$ In this study, around $24.89 \%$ of them mentioned that hot/cold food affecting the menstrual cycle, and $83.54 \%$ of them considered menstruation was as impure blood, but less percentage ${ }^{12}$ was had been reported by Paul et al. ${ }^{5}$ Around $36.28 \%$ of the participants mentioned that awareness about problems likely to arise due to unhygienic practice, but higher percentages (58\%) were reported by Paul et al. ${ }^{5}$

Around $57.38 \%$ of the study participants knew about menstruation before menarche, which was similar to Verma et al., ${ }^{23}$ where $58.3 \%$ of females had reported having prior knowledge about menstruation ${ }^{24}$ in this study. More than half of the study people were not aware of menarche menstruation. Presumably, every female child should be aware of menstrual before menarches play an extended role in maintaining and avoiding menstrual hygiene.

Regarding the cause of menstruation, the majority (75.52\%) of the study participants supposed that menstruation is natural

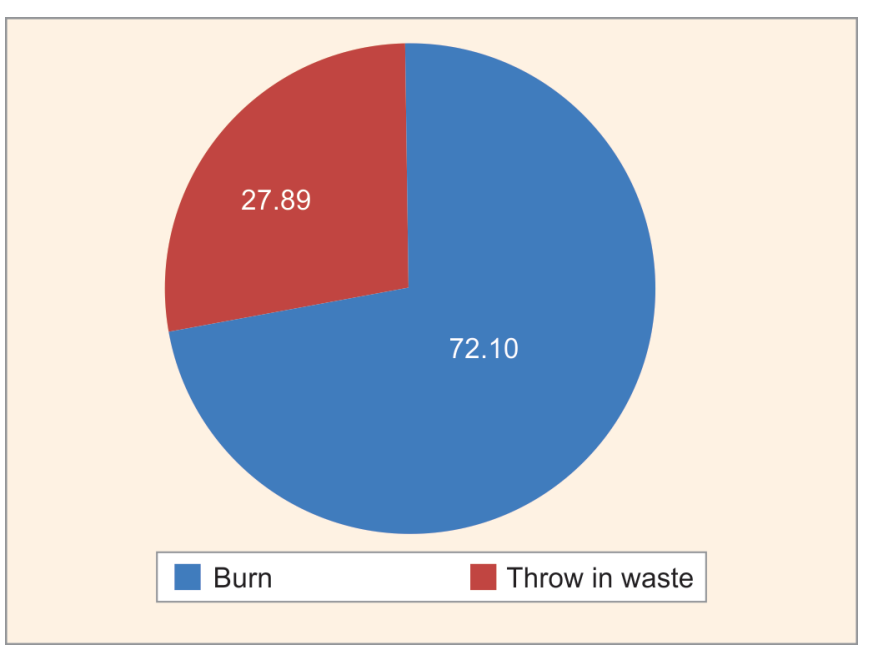

Fig. 4: Dispose of menstruation pads

physiology which was somewhat similar to the finding by Verma et al. where $85.83 \%$ of girls believed it to be a natural phenomenon; ${ }^{23}$ it was evident that a $12.23 \%$ of females in the study were not the aware cause of menstruation and fewer believed $6.3 \%$ that it was due to God's curse which was the complete wrong perception of rural area's females which was similar to finding by Paul et al., where $6.5 \%$ females have a perception the same.

The finding regarding the source of blood in menstruation, $50.20 \%$ of the study participants did not know about the source of menstrual blood, which was lower than a finding by Pundkar et al. where reported $70.71 \%$ (females did not know the source). ${ }^{24}$ The present study showed that most participants (83.54\%) believed menstruation blood as impure blood, which was high to findings by Paul et al., where $12 \%$ mentioned it as dirty blood. Around $30 \%$ of the participants mentioned that the uterus was the source of blood, but higher percentages (58\%) had been reported by Misra et al. ${ }^{11}$

The present study finding indicated that most participants acquired knowledge about menstruation from their primary source-mother and our findings have been supported by Paul et al. ${ }^{5}$ and Johnson et al. ${ }^{25}$ In contrast, most mothers were illiterate, and similar findings have been reported by Paul et al. ${ }^{5}$ Around $52.36 \%$ of participates were water used for cleaning genitalia in the present study in the rural area, and the finding supported by Mathiyalagen et al., ${ }^{22}$ whereas the most common agent was only water (53.7\%). In the present study, the commonly practiced method of disposing of the absorbent was burning, similar to the findings by another Pundkar et al. ${ }^{24}$ Numerous studies have been reported improper disposal of sanitary pads/cloths is a threat to the environment and affect people's health. In the present study, it was observed that improper disposal of sanitary pads or cloths by about $72.10 \%$ of study participants (due to lack of proper knowledge about menstrual hygiene practice and they belong to the rural area). Various studies have already defined the disposal of used sanitary pads or cloths thrown in waste by the proper packing. ${ }^{22}$ Also, lack of knowledge about personal hygiene care and unsafe sanitary products, improper perineal washing, and other practices have led to various gynecological problems (cervical cancer and ovarian cancer, infertility) among women in many studies. Therefore, they should be encouraged to use safe, sanitary pads with health education by health workers and follow the regular cleaning with 
soap, water, and antiseptic should be advised to every rural woman of all age groups.

\section{Conclusion}

Menstruation is a milestone or natural event in a females' life, a vital sign of the reproductive age group, and the beginning of a females' reproductive life. Menstrual hygiene practices are an essential phenomenon of reproductive female health. The present study tries to defined awareness about menstrual hygiene practice, and it is good habits for good health even also for the environment or all living one, though knowledge before menarche of females was not satisfactory. Still, many females follow restrictions in rural areas and enforced various activities during menstruation cycles of women. Menstrual hygiene practice, especially disposal, needs unique reconsideration. Sanitary napkin use and perineal washing were satisfactory among the participants. This study is limited by its single setting as well as self-reported responses. Moreover, in-depth exploration of menstrual behavior was beyond the scope of this study. Further studies with more qualitative nature are recommended to explore the in-depth factors responsible for poor menstrual hygiene practices.

\section{Recommendation}

For the country's development, women should be healthy; teachers, parents, and healthcare workers can successfully run education, healthcare, and awareness programs and focus on menstrual hygiene practices. The government should include health education programs in every school curriculum and even colleges and universities. Between time duration, different educational and awareness programs and campus should be implemented in rural and urban areas, and safe, sanitary pads, the origin of mensuration, and hygiene practices should be encouraged. Primary care physicians should run the education class for rural people about menstruation, menstrual hygiene management, the importance of toilets at homes, diseases related to reproductive tract due to poor hygiene, and so forth, and comprehensive policy menstrual hygiene should be promoted at every level.

\section{Limitation of Study}

For the present study, only Gynaecology OPD women were taken. Therefore, they are not indicative of both the community in general.

\section{References}

1. Gupta M, Tiwari S, Wavare RR. Awareness and practices regarding menstrual hygiene among women of reproductive age group attending a tertiary care hospital of Indore, India. Nat J Commu Med 2015;6(2):247-277.

2. Ahuja A, Tiwari S. Awareness about pubertal changes among adolescent girls. J Family Welfare 1995;41(1):46-50.

3. Chaudhari RH, Socio-economic demographic and reproductive health profile of adolescents in the SAARC countries. Paper presented in south Asia Conference on Adolescents; 21-23 July 1998; New Delhi, India.

4. Khanna A, Goyal RS, Bhawsar R. Menstrual practices and reproductive problems: a study of adolescent girls in Rajasthan. J Health Manage 2005;7(1):91-97. DOI: 10.1177/097206340400700103.

5. Paul KK, Chaudhuri S, Maiti A. Menstrual hygiene practices among women aged 15-49 years attending a medical college hospital in Kolkata: a cross-sectional study. J Family Med Prim Care 2020;9(9):4699-4704. DOI: 10.4103/jfmpc.jfmpc_718_20.
6. Thakur H, Aronsson A, Bansode S, et al. Knowledge, practices, and restrictions related to menstruation among young women from low socio-economic community in Mumbai, India. Front Public Health 2014;2:72. DOI: 10.3389/fpubh.2014.00072.

7. Mudey AB, Keshwani N, Mudey GA, et al. A cross-sectional study on the awareness regarding safe and hygienic practices amongst school going adolescent girls in the rural areas of Wardha district. Global J Health Sci 2010;2(2):225-231. DOI: 10.5539/gjhs.v2n2p225.

8. Ghattargi $\mathrm{CH}$, Deo DS. Preparation and practices regarding menstruation: a comparative study in rural and urban adolescent girls. Indian J Commu Med 2005;30(1):10-14.

9. Dasgupta A, Sarkar M. Menstrual hygiene: how hygienic is the adolescent girl? Indian J Commu Med 2008;33(2):77-80. DOI: 10.4103/0970-0218.40872.

10. Yasmin S, Manna N, Mallik S, et al. Menstrual hygiene among adolescent school students: an in- depth cross-sectional study in an urban community of West Bengal, India. IOSR J Dent Med Sci 2013;5(6):22-26. DOI: 10.9790/0853-0562226.

11. Misra P, Upadhyay RP, Sharma V, et al. A community-based study of menstrual hygiene practices and willingness to pay for sanitary napkins among women of a rural community in northern India. Natl Med J India 2013;26(6):335-337.

12. Parashar A, Gupta B, Bhardwaj A, et al. Prevalence of RTls among women of reproductive age group in Shimla city. Indian J Commu Med 2006;31(1):15. DOI: 10.4103/0970-0218.54924.

13. Langer B, Mahajan R, Gupta RK, et al. Impact of menstrual awareness and knowledge among adolescents in a rural area. Indian J Commu Heal 2015;27:456-461.

14. Parashar A, Gupta B, Bhardwaj A, et al. Menstrual hygiene among married women: a hospital based cross-sectional study in an urban slum of Mumbai, India. Int J Commu Med Public Heal 2016;3:57-61. DOI: 10.4103/0970-0218.54924.

15. Shanbhag D, Shilpa R, D'Souza N, et al. Perceptions regarding menstruation and practices during menstrual cycles among high school going adolescent girls in resource limited settings around Bangalore city, Karnataka, India. Int J Collab Res Intern Med Public Heal 2012;4:1353-1362.

16. Khan S, Jha D, Ansari N. Menstrual hygiene knowledge, practices and acne problems among adolescent and young adult females: a cross sectional study. Int J Emerg Technol Innov Res 2020;7:221-228.

17. Juyal R, Kandpal SD, Semwal J. Menstrual hygiene and reproductive morbidity in adolescent girls in Dehradun, India. Bangladesh J Med Sci 2014;13:8-12.

18. Drakshayani Devi K, Venkata Ramaiah P. A study on menstrual hygiene among rural adolescent girls. Indian J Med Sci 1994;48(6):139-143.

19. Kamath $R$, Ghosh D, Lena A, et al. A study on knowledge and practices regarding menstrual hygiene among rural and urban adolescent girls in Udupi Taluk, Manipal, India. Glob J Med Public Health 2013;2:1-9.

20. Balamurugan SS, Shilpa S, Shaji S. A community based study on menstrual hygiene among reproductive age group women in a rural area, Tamil Nadu. J Basic Clin Reprod Sci 2014(2):3. DOI: 10.4103/2278960X.140040.

21. Thakre SB, Thakre SS, Reddy M, et al. Menstrual hygiene: knowledge and practice among adolescent school girls of Saoner, Nagpur District. J Clin Diagnostic Res 2011;5:1027-1033.

22. Mathiyalagen P, Peramasamy B, Vasudevan K, et al. A descriptive crosssectional study on menstrual hygiene and perceived reproductive morbidity among adolescent girls in a union territory, India. J Family Med Prim Care 2017;6(2):360-365. DOI: 10.4103/2249-4863.220031.

23. Verma P, Ahmad S, Srivastava RK. Knowledge and practices about menstrual hygiene among higher secondary school girls. Indian J Community Health 2013;25:265-271.

24. Pundkar RD, Zambare MB, Baride JP. The knowledge and practice of menstrual hygiene among adolescent girls in one of the municipal corporation school of Ahmednagar. VIMS Health Sci J 2014;1:118-124.

25. Johnson LR, Ravichandran M, Thomas MR, et al. Adolescent reproductive and sexual health (ARSH): what do tribal schoolgirls know and do? Acad Med J India 2014;2:14-17. 